\title{
MicroRNA-149-3p inhibits cell proliferation by targeting AKT2 in oral squamous cell carcinoma
}

\author{
QIN SHEN* ${ }^{*}$ HONG ZHU*, QIAOLING LEI, LUYUAN CHEN, DAJIANG YANG and WEN SUI \\ Department of Stomatology Center, Shenzhen Hospital, Southern Medical University, \\ Shenzhen, Guangdong 518100, P.R. China
}

Received June 12, 2020; Accepted November 17, 2020

DOI: $10.3892 / \mathrm{mmr} .2020 .11811$

\begin{abstract}
MicroRNAs (miRs) exhibit oncogenic or tumor suppressive functions that contribute to the initiation and development of various types of human cancer. miR-149-3p has been reported to serve multiple roles in the regulation of proliferation, apoptosis and metastasis. However, the effects and detailed mechanism of miR-149-3p in oral squamous cell carcinoma (OSCC) remain unclear. In the present study, miR-149-3p mimic, mimic control, miR-149-3p inhibitor and inhibitor control were transiently transfected into Cal27 and SCC-9 cells. The viability, proliferation and apoptosis of OSCC cells were determined using Cell Counting Kit-8, colony formation and Annexin $\mathrm{V}$ assays, respectively. The mRNA expression levels of miR-149-3p and AKT2 were determined by reverse transcription-quantitative PCR. The protein expression levels of AKT2, cleaved caspase-3 and cleaved PARP were examined by western blot analysis. The binding of miR-149-3p to the AKT2 3'-untranslated region was evaluated by a dual luciferase reporter assay. In the present study, overexpression of miR-149-3p reduced the viability and proliferation of OSCC cells. By contrast, increased cell viability and proliferation was observed in miR-149-3p-deficient OSCC cells. Dual luciferase reporter assay indicated that miR-149-3p significantly decreased the luciferase activity of the wild-type AKT2 3'-untranslated region. Moreover, overexpression of miR-149-3p downregulated the mRNA and protein expression levels of AKT2, suggesting that miR-149-3p was a negative modulator of AKT2. Restoration of AKT2 efficiently reversed the miR-149-3p-mediated reduction in the proliferative
\end{abstract}

Correspondence to: Dr Qin Shen or Dr Wen Sui, Department of Stomatology Center, Shenzhen Hospital, Southern Medical University, 1333 Xinhu Road, Shenzhen, Guangdong 518100, P.R. China

E-mail: zhouxi1245@smu.edu.cn

E-mail:wendysui@smu.edu.cn

*Contributed equally

Key words: oral squamous cell carcinoma, microRNA-149-3p, AKT2, cell proliferation capacity of OSCC cells. In addition, miR-149-3p enhanced the sensitivity of OSCC cells to the chemotherapeutic drug 5-fluorouracil. Taken together, the current findings revealed an inhibitory effect of miR-149-3p on the proliferation of OSCC cells through the post-transcriptional suppression of AKT2, and indicated a potential chemosensitizing function of miR-149-3p for the treatment of patients with OSCC.

\section{Introduction}

Oral squamous cell carcinoma (OSCC) is one of the most common malignancies worldwide. It was estimated that $>50,000$ new cases of OSCC were reported in the United States in 2018, which resulted in 10,000 deaths (1). The current therapies used to treat OSCC include surgery, chemotherapy and radiotherapy (2). Although advances in the diagnosis and clinical treatment of OSCC have been made, the 5-year survival rates of patients with OSCC remain relatively low, due to the aggressive progression and recurrence of the disease $(3,4)$. Therefore, it is crucial to identify potential biomarkers to improve the prognosis and therapeutic strategies of OSCC.

MicroRNAs (miRNAs/miRs) are short non-coding RNAs that regulate the degradation and translational process of mRNAs by directly binding to the 3'-untranslated region (3'-UTR) of target genes $(5,6)$. Accumulating evidence has indicated that the dysregulation of miRNAs contributes to the initiation and development of various types of human cancer, including pancreatic cancer (7), gastric cancer (8) and breast cancer (9). Numerous studies have revealed that miR-149-3p acts as a tumor suppressor. For example, miR-149-3p was shown to modulate polo-like kinase 1 (PLK1) levels by competing with heterogeneous nuclear ribonucleoprotein $\mathrm{K}$ in the 3'-UTR of PLK1 mRNA, which led to the decreased growth of HeLa cells (10). In addition, miR-149-3p downregulated S100A4 expression, and suppressed the proliferation and metastasis of bladder cancer (11). Conversely, a recent study reported that $\mathrm{miR}-149-3 \mathrm{p}$ attenuated the apoptosis and depletion of $\mathrm{CD}^{+} \mathrm{T}$ cells, suggesting a potential protective role of miR-149-3p in $\mathrm{CD}^{+} \mathrm{T}$ cells (12). Moreover, miR-149-3p promoted the aggressiveness of cancer cells via inhibition of DAB2-interacting protein in a cell-autonomous and non-autonomous manner (13). However, to the best of our knowledge, the functional role and mechanisms of miR-149-3p in OSCC remain unknown. 
In the present study, overexpression of miR-149-3p attenuated cell viability and proliferation, whereas miR-149-3p knockdown augmented the viability and proliferation of OSCC cells. The data further demonstrated that miR-149-3p decreased AKT2 expression by directly binding to the 3'-UTR of AKT2 mRNA. Moreover, AKT2 efficiently restored the inhibited proliferative capacity of OSCC cells induced by miR-149-3p. Notably, miR-149-3p-overexpressing OSCC cells exhibited higher sensitivity to the chemotherapeutic drug 5-fluorouracil (5-Fu). Taken together, to the best of our knowledge, the present study was the first to indicate that miR-149-3p inhibited the proliferation of OSCC cells and improved the efficacy of 5-Fu in OSCC cells by targeting AKT2.

\section{Materials and methods}

Cell culture and reagents. The human OSCC Cal27 and SCC-9 cells were purchased from American Type Culture Collection. Cal-27 cells were grown in DMEM (Gibco; Thermo Fisher Scientific, Inc.) with 10\% FBS (Gibco; Thermo Fisher Scientific, Inc.), and SCC-9 cells were cultured in DMEM/Ham's F-12 medium (Gibco; Thermo Fisher Scientific, Inc.) supplemented with $400 \mathrm{ng} / \mathrm{ml}$ hydrocortisone (Sigma-Aldrich; Merck KGaA) and $10 \%$ FBS, according to the manufacturer's instructions. The MSK-Leuk1 Cells were maintained in EpiLife ${ }^{\mathrm{TM}}$ Medium (Gibco; Thermo Fisher Scientific, Inc.) supplemented with Human Keratinocyte Growth Supplement (Gibco; Thermo Fisher Scientific, Inc.). Cells were maintained in an atmosphere containing $5 \% \mathrm{CO}_{2}$ at $37^{\circ} \mathrm{C}$.

The pcDNA3-Myr-HA-Akt2 (plasmid no. 9016; Addgene, Inc.) was provided as a gift from Professor William Sellers (Dana-Farber Cancer Institute, USA). 5-Fu was purchased from Selleck Chemicals and crystal violet was obtained from Sangon Biotech Co., Ltd.

Transfection. The commercial miR-149-3p mimic (cat. no. miR10004609), mimic control (cat. no. miR1N0000001), miR-149-3p inhibitor (cat. no. miR20004609) and inhibitor control (cat. no. miR2N0000001) were purchased from Guangzhou RiboBio Co., Ltd. Cal27 and SCC-9 cells were grown to $\sim 50 \%$ confluence, and then miR-149-3p mimic (50 nM), mimic control (50 nM), miR-149-3p inhibitor (100 nM) or inhibitor control $(100 \mathrm{nM})$ were transiently transfected into OSCC cells using Lipofectamine ${ }^{\circledR}$ RNAiMAX Transfection Reagent (Invitrogen; Thermo Fisher Scientific, Inc.), according to the manufacturer's instructions. After $48 \mathrm{~h}$ of transfection at $37^{\circ} \mathrm{C}$, cells were harvested for subsequent reverse transcription-quantitative polymerase chain reaction (RT-qPCR) analysis. For AKT2 overexpression, Cal27 and SCC-9 cells were plated into 6-well plates, and grown to $\sim 50 \%$ confluence. Then, $4 \mu \mathrm{g}$ pcDNA3-Myr-HA-Akt2 plasmid or empty pcDNA3 plasmid was transiently transfected into OSCC cells using Lipofectamine ${ }^{\circledR}$ 3,000 Transfection Reagent (Invitrogen; Thermo Fisher Scientific, Inc.). After $48 \mathrm{~h}$ of transfection at $37^{\circ} \mathrm{C}$, cells were harvested for subsequent RT-qPCR and western blot analysis.

RNA extraction and RT- $q P C R$. Total RNA was isolated from OSCC cells using TRIzol ${ }^{\circledR}$ reagent (Invitrogen; Thermo Fisher Scientific, Inc.). The cDNA was reverse transcribed from RNA at $37^{\circ} \mathrm{C}$ for $1 \mathrm{~h}$ and $85^{\circ} \mathrm{C}$ for 5 min using an All-in-One
cDNA Synthesis SuperMix (GeneCopoeia, Inc.). For miRNA quantification, the expression levels of miR-149-3p were detected using an All-in-one miRNA qPCR kit (GeneCopoeia, Inc.) according to the manufacturer's instructions. The following thermocycling conditions for qPCR were used: Initial denaturation at $95^{\circ} \mathrm{C}$ for $10 \mathrm{~min}$; and 40 cycles of denaturation at $95^{\circ} \mathrm{C}$ for $10 \mathrm{sec}$, annealing at $60^{\circ} \mathrm{C}$ for $20 \mathrm{sec}$, and extension at $72^{\circ} \mathrm{C}$ for $15 \mathrm{sec}$. For AKT2 quantification, the expression levels of AKT2 were detected with TB Green ${ }^{\circledR}$ Premix Ex Taq ${ }^{\mathrm{TM}}$ II (Tli RNaseH Plus) (Takara Biotechnology Co., Ltd.). The following thermocycling conditions for qPCR were used: Initial denaturation at $95^{\circ} \mathrm{C}$ for $5 \mathrm{~min}$; and 40 cycles of denaturation at $95^{\circ} \mathrm{C}$ for $10 \mathrm{sec}$, and annealing and extension at $60^{\circ} \mathrm{C}$ for $45 \mathrm{sec}$. The following primers were used: miR-149-3p forward, 5'-ACAGGGAGGGACGGGGG-3' and reverse, 5'-CAGTGCAGGGTCCGAGGTATT-3'; U6 forward, 5'-CAAATTCGTGAAGCGTTCCATA-3' and reverse, 5'-AGT GCAGGGTCCGAGGTATTC-3'; AKT2 forward, 5'-TCCGAG GTCGACACAAGGTA-3' and reverse, 5'-CTGGTCCAGCTC CAGTAAGC-3'; $\beta$-actin forward, 5'-CTCCATCCTGGCCTC GCTGT-3' and reverse, 5'-GCTGTCACCTTCACCGTTCC-3'. The $2^{-\Delta \Delta \mathrm{Cq}}$ method was used for all qPCR quantification (14). U6 snRNA and $\beta$-actin were used as an endogenous control for miR-149-3p and AKT2, respectively.

Western blot analysis. OSCC cells were collected and lysed with NP-40 lysis buffer (Beyotime Institute of Biotechnology). Protein concentration was quantified using a Pierce Detergent Compatible Bradford Assay kit (Pierce; Thermo Fisher Scientific, Inc.). Cell lysates $(30 \mu \mathrm{g})$ were resolved by SDS-PAGE on $12 \%$ gel, and subsequently transferred to PVDF membranes. After blocking with $5 \%$ skimmed milk at room temperature for $1 \mathrm{~h}$, the membrane was incubated overnight at $4^{\circ} \mathrm{C}$ with the following primary antibodies: AKT2 (1:1,000; cat. no. 3063; Cell Signaling Technology, Inc.), cleaved caspase-3 (1:1,000; cat. no. 9664; Cell Signaling Technology, Inc.), cleaved PARP (1:1,000; cat. no. 5625; Cell Signaling Technology, Inc.) and $\beta$-actin (1:1,000; cat. no. 8457; Cell Signaling Technology, Inc.). After incubation with the primary antibody, the membrane was washed in TBS with $0.05 \%$ Tween-20 three times, and then incubated with a horseradish peroxidase-conjugated goat anti-rabbit antibody (1:3,000; cat. no. 7074; Cell Signaling Technology, Inc.) at room temperature for $1 \mathrm{~h}$. The protein bands were developed using Immobilon ${ }^{\mathrm{TM}}$ Western Chemiluminescent HRP Substrate (EMD Millipore). The images were analyzed by ImageJ software (version no. 1.52a; National Institutes of Health) using $\beta$-actin as the loading control.

Cell Counting Kit-8 (CCK-8) assay. Cell viability was estimated using the CCK- 8 assay (Dojindo Molecular Technologies, Inc.), according to the manufacturer's protocol. Briefly, OSCC cells transfected with miR-149-3p mimic or inhibitor were seeded in 96 -well plates $\left(5 \times 10^{3}\right.$ cells/well). After $24 \mathrm{~h}$ of transfection at $37^{\circ} \mathrm{C}$, the cells were cultured for another $24,48,72$ or $96 \mathrm{~h}$ and then incubated with $10 \mu \mathrm{l}$ CCK-8 reagent at $37^{\circ} \mathrm{C}$ for $2 \mathrm{~h}$. For 5-Fu treatment, the cells were treated with $10 \mu \mathrm{M} 5$-Fu (Selleck Chemicals) at $37^{\circ} \mathrm{C}$ for $24 \mathrm{~h}$, and then incubated with $10 \mu \mathrm{lCCK}-8$ reagent at $37^{\circ} \mathrm{C}$ for $2 \mathrm{~h}$. The absorbance of samples at $450 \mathrm{~nm}$ was determined using a microplate reader. 
Colony formation assay. OSCC cells transfected with miR-149-3p mimic or inhibitor were plated in 24-well plates (500 cells/well). Cells were grown to form colonies for 12 days. Subsequently, the colonies were stained with crystal violet at room temperature for $20 \mathrm{~min}$, and colony numbers were calculated using ImageJ (version number 1.52a) software (National Institutes of Health).

Flow cytometry assay. For the dose curve of 5-Fu treatment, OSCC cells transfected with miR-149-3p mimic or mimic control were treated with 5,10 or $20 \mu \mathrm{M} 5-\mathrm{Fu}$ at $37^{\circ} \mathrm{C}$ for $24 \mathrm{~h}$. For the time curve of 5-Fu treatment, OSCC cells transfected with miR-149-3p mimic or mimic control were treated with $10 \mu \mathrm{M} 5-\mathrm{Fu}$ at $37^{\circ} \mathrm{C}$ for 12,24 or $48 \mathrm{~h}$. Then, cells were harvested and stained Annexin V-FITC and PI at room temperature for 15 min using the Annexin V-FITC Apoptosis Detection Kit (Nanjing KeyGen Biotech Co., Ltd.), according to the manufacturer's instructions. Subsequently, the cells were analyzed with a flow cytometer (FACSAria ${ }^{\mathrm{TM}}$; BD Biosciences) and FlowJo software (version 10.0.7; Tree Star, Inc.). The cells in Q2 (late-stage apoptosis) and Q3 (early-stage apoptosis) were considered to be apoptotic cells.

Dual luciferase reporter assay. The target genes of miR-149-3p were predicted using TargetScan (version 7.2; http://www. targetscan.org/vert_72/) and miRDB (version 6.0; http://www. mirdb.org/index.html). The mutated (MT) AKT2 3'-UTR fragments containing the putative binding site of miR-149-3p were generated using Fast MultiSite Mutagenesis System (cat. no. FM201; TransGen Biotech Co., Ltd.), according to the manufacturer's protocol. The human wild-type (WT) and MT AKT2 3'-UTR fragments were inserted into the pEZX-FR02 luciferase reporter vector (GeneCopoeia, Inc.). Cal27 and SCC-9 cells were seeded in 48-well plates, and grown to $\sim 50 \%$ confluence. Then, the cells were co-transfected with $0.5 \mu \mathrm{g}$ WT or MT AKT2 3'-UTR and $50 \mathrm{nM}$ miR-149-3p mimic or mimic control using Lipofectamine 3,000 Transfection Reagent. After transfection for $36 \mathrm{~h}$ at $37^{\circ} \mathrm{C}$, the luciferase activity was detected using the Dual-Luciferase Reporter Assay system (Promega Corporation). The firefly luciferase activity was normalized to the Renilla luciferase activity.

Statistical analysis. All quantitative data are presented as the mean \pm SD for at least three independent experiments. Student's t-test or one-way ANOVA followed by Tukey's post hoc test were used to assess the differences between two and more than two groups, respectively. Pearson correlation analysis was used to analyze the correlation between the expression levels of miR-149-3p and AKT2 in TCGA head and neck squamous cell carcinomadataset(https://www.cancer.gov/about-nci/organization/ccg/research/structural-genomics/tcga) (15). The statistical analyses were performed using SPSS software version 22.0 (IBM Corp.). $\mathrm{P}<0.05$ was considered to indicate a statistically significant difference.

\section{Results}

miR-149-3p inhibits the proliferation of OSCC cells. To explore the role of miR-149-3p in OSCC tumorigenesis, the expression levels of miR-149-3p were detected in OSCC cell lines (Cal27

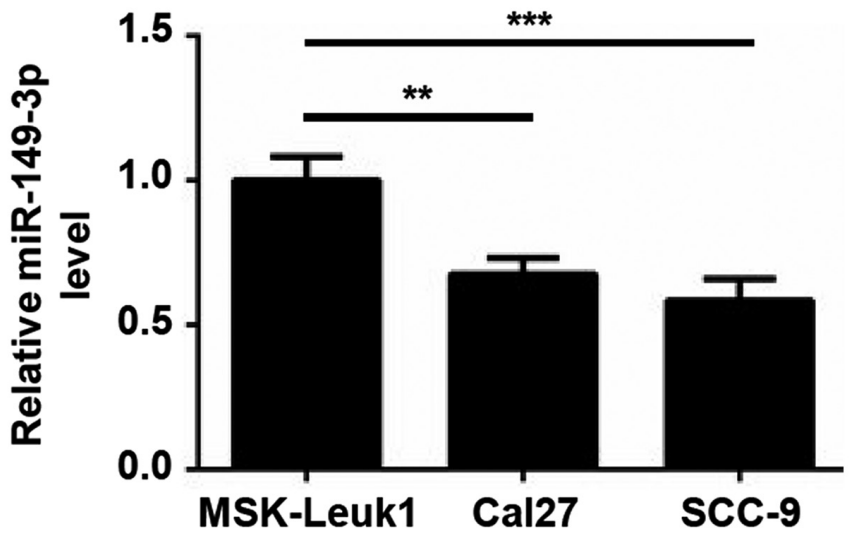

Figure 1. Analysis of miR-149-3p expression in OSCC and non-tumorigenic oral epithelial cell lines. Reverse transcription-quantitative PCR analysis of miR-149-3p expression levels in OSCC cells (Cal27 and SCC-9) and non-tumorigenic oral epithelial cell (MSK-Leuk1). ${ }^{* *} \mathrm{P}<0.01$ and ${ }^{* * * *} \mathrm{P}<0.001$. OSCC, oral squamous cell carcinoma; miR-149-3p, microRNA-149-3p.

and SCC-9 cells) and in the non-tumorigenic oral epithelial cell line MSK-Leuk1. As shown in Fig. 1, lower expression levels of miR-149-3p were observed in Cal27 and SCC-9 cells compared with in MSK-Leuk1 cells, indicating that miR-149-3p may be involved in OSCC progression. To investigate the functional effect of miR-149-3p on the proliferation of OSCC cells, Cal27 and SCC-9 cells were transfected with the miR-149-3p mimic or mimic control. Post-transfection, the cells were cultured for $48 \mathrm{~h}$ and the expression levels of miR-149-3p were verified by RT-qPCR analysis. The results revealed an $~ 8.1-$ and 5.4-fold increase in the expression levels of miR-149-3p in miR-149-3p mimic-transfected Cal27 and SCC-9 cells compared with in mimic control-transfected cells, respectively (Fig. 2A and B). CCK-8 assays revealed that miR-149-3p overexpression significantly suppressed the viability of OSCC cells (Fig. 2C and D). Moreover, the overexpression of miR-149-3p diminished the colony-forming ability of OSCC cells (Fig. 2E and F). These data indicated that miR-149-3p inhibited the proliferation of OSCC cells.

Knockdown of miR-149-3p promotes the proliferation of OSCC cells. Subsequently, the effects of miR-149-3p knockdown on the proliferation of OSCC cells were investigated. The expression levels of miR-149-3p were downregulated in OSCC cells transfected with the miR-149-3p inhibitor compared with those transfected with the inhibitor control, as determined by RT-qPCR analysis (Fig. 3A and B). Silencing of miR-149-3p efficiently augmented the viability of OSCC cells (Fig. 3C and D). Similar results were observed in the colony formation assay (Fig. 3E and F). These data indicated that miR-149-3p knockdown promoted the proliferation of OSCC cells.

AKT2 is a direct target of miR-149-3p. To explore the molecular mechanisms by which miR-149-3p suppresses the proliferation of OSCC cells, the target genes of miR-149-3p were analyzed using TargetScan and miRDB databases; the genes predicted by both analyses were considered potential target genes of miR-149-3p. According to this strategy, a miR-149-3p binding site was identified in the 3'-UTR of AKT2 mRNA (Fig. 4A). 

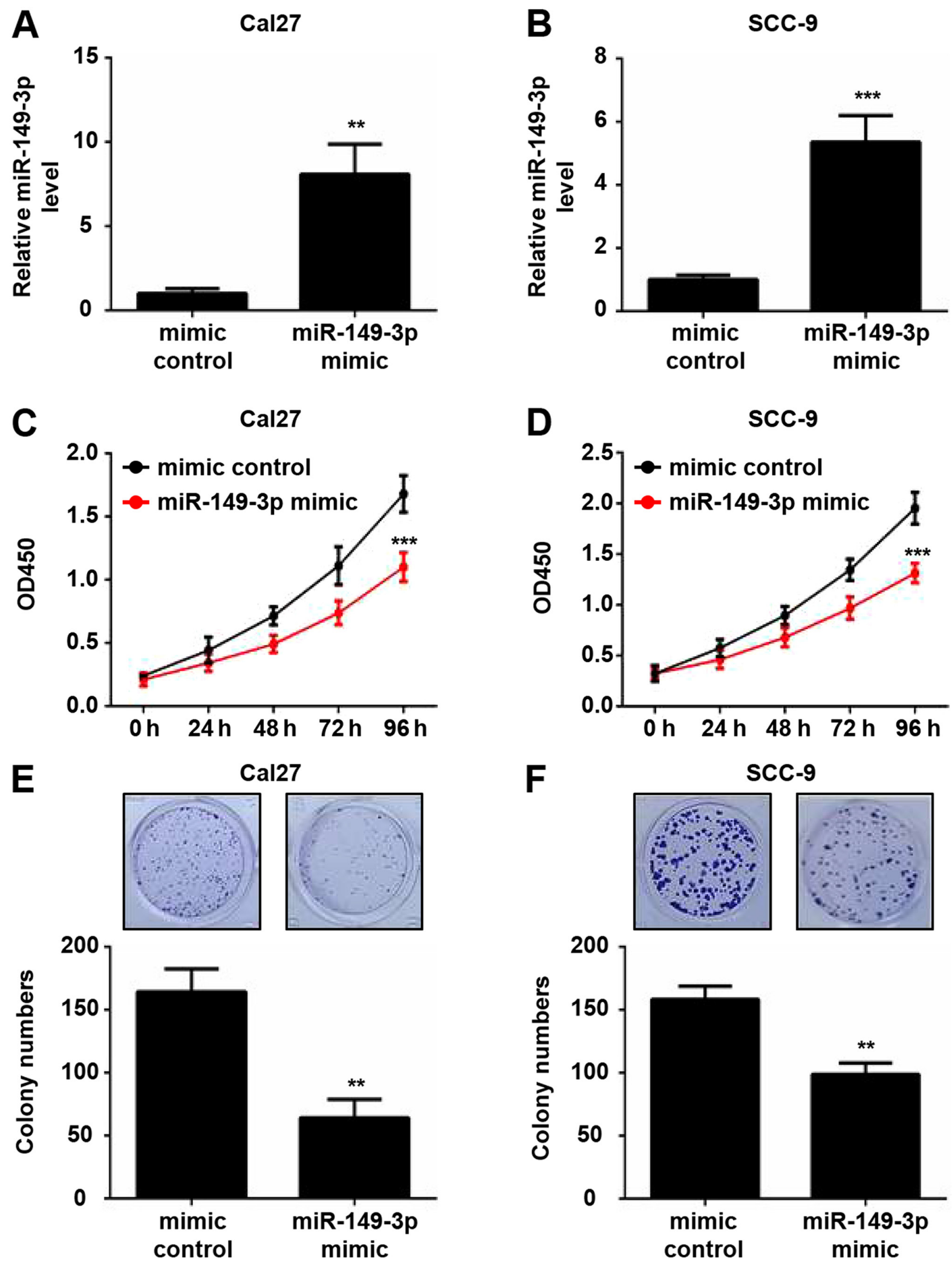

Figure 2. miR-149-3p mimic inhibits the proliferation of oral squamous cell carcinoma cells. (A and B) Reverse transcription-quantitative PCR analysis of miR-149-3p expression levels in Cal27 and SCC-9 cells transfected with miR-149-3p mimic or mimic control. (C and D) Viability of Cal27 and SCC-9 cells transfected with miR-149-3p mimic or mimic control, as determined using a Cell Counting Kit-8 assay. (E and F) Proliferation of Cal27 and SCC-9 cells transfected with miR-149-3p mimic or mimic control was examined by colony formation assay. Data are presented as the mean $\pm \mathrm{SD} .{ }^{* * *} \mathrm{P}<0.01$ and ${ }^{* * * *} \mathrm{P}<0.001$ vs. mimic control. miR-149-3p, microRNA-149-3p; OD, optical density.

Accumulating evidence has confirmed that AKT2 is essential for cell survival and proliferation $(16,17)$. Consequently, the AKT2 gene was selected for further investigation. To assess whether
AKT2 is a direct target of miR-149-3p, luciferase reporter plasmids that contain WT or MT 3'-UTR target sequences of AKT2 were constructed. The dual luciferase reporter assay 

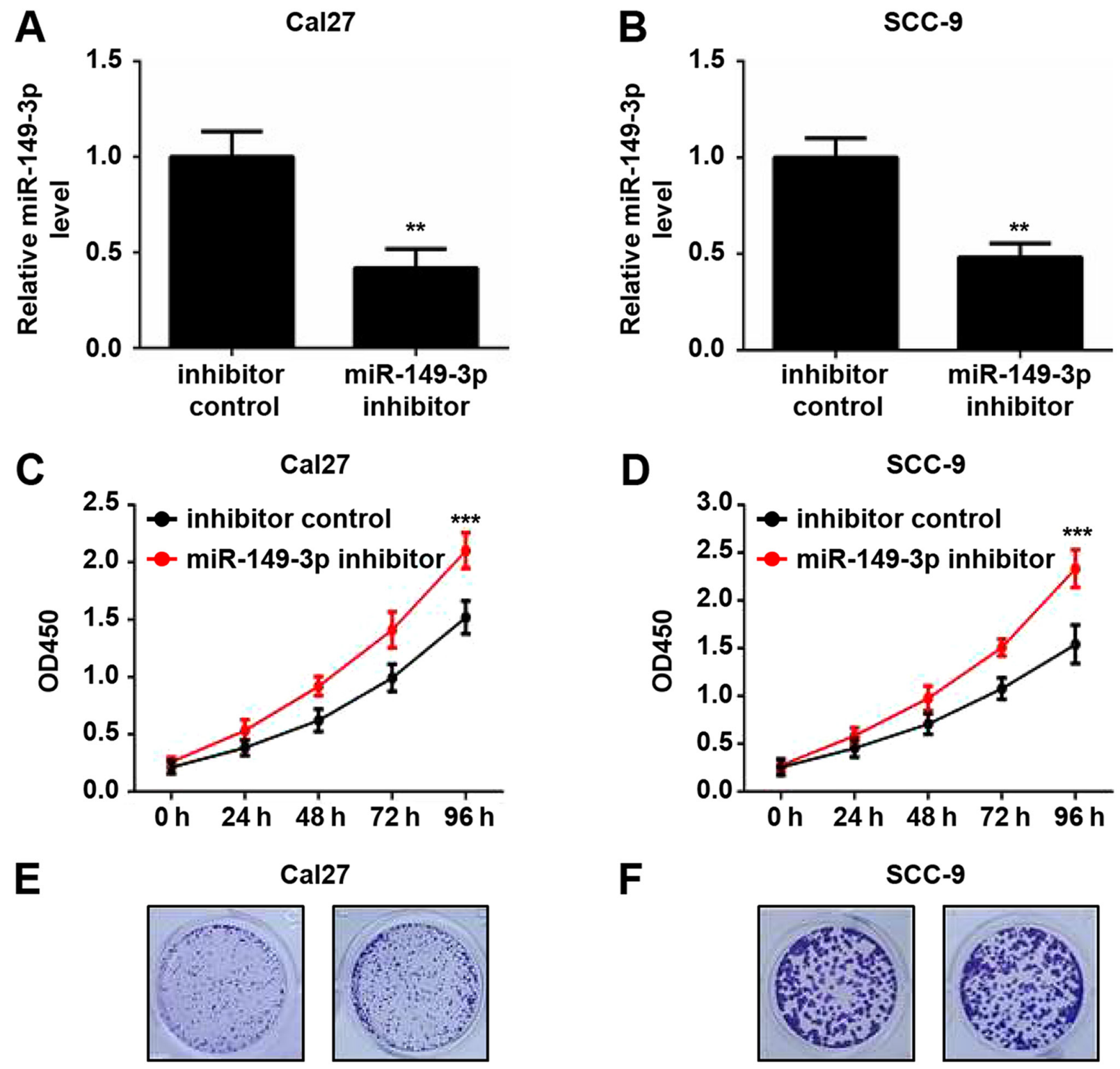

F SCC-9
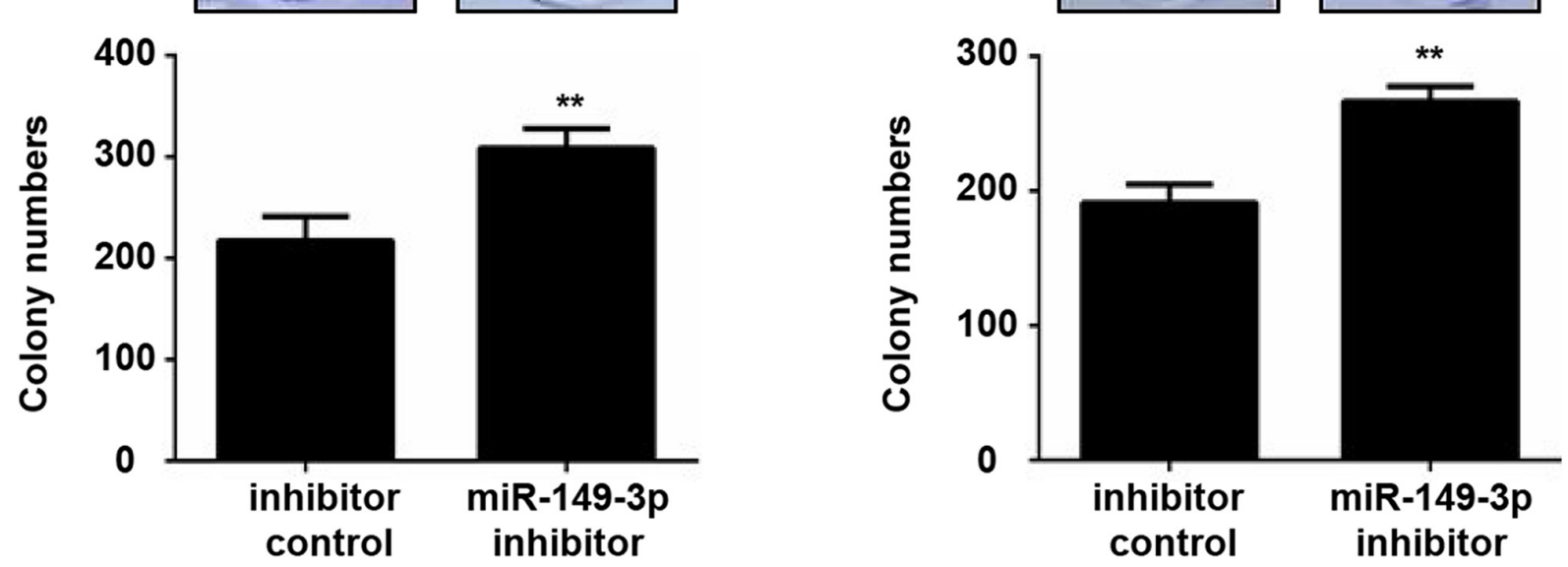

Figure 3. miR-149-3p inhibitor promotes the proliferation of oral squamous cell carcinoma cells. (A and B) Reverse transcription-quantitative PCR analysis of miR-149-3p expression levels in Ca127 and SCC-9 cells transfected with miR-149-3p inhibitor or inhibitor control. (C and D) Viability of Cal27 and SCC-9 cells transfected with miR-149-3p inhibitor or inhibitor control, as determined using a Cell Counting Kit-8 assay. (E and F) Proliferation of Cal27 and SCC-9 cells transfected with miR-149-3p inhibitor or inhibitor control was examined using a colony formation assay. Data are presented as the mean $\pm \mathrm{SD}$. ${ }^{* *} \mathrm{P}<0.01$ and ${ }^{* * *} \mathrm{P}<0.001$ vs. inhibitor control. miR-149-3p, microRNA-149-3p; OD, optical density.

demonstrated that the miR-149-3p mimic markedly decreased the luciferase activity of WT AKT2 3'-UTR-transfected Cal27 and SCC-9 cells compared with the mimic control group
(Fig. 4B and C). Conversely, no effects were noted on the luciferase activity of MT AKT2 3'-UTR following transfection with the miR-149-3p mimic (Fig. 4B and C). Moreover, the 
A

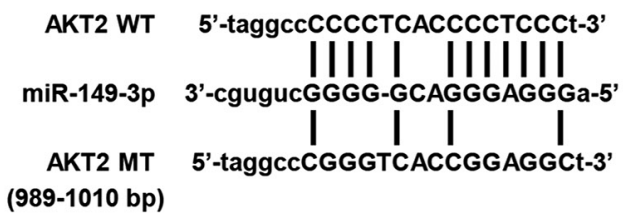

D

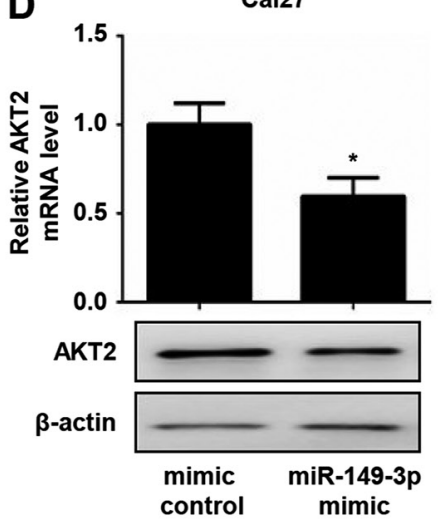

B

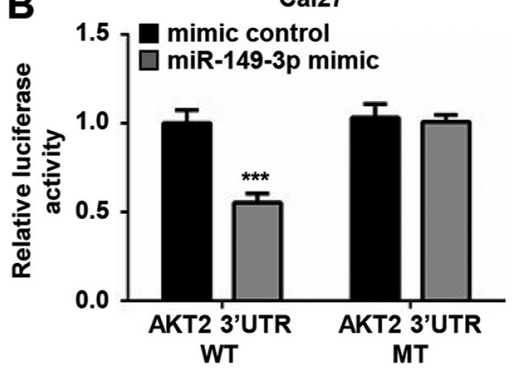

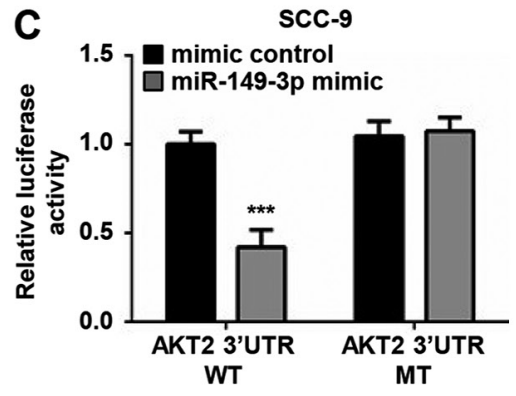

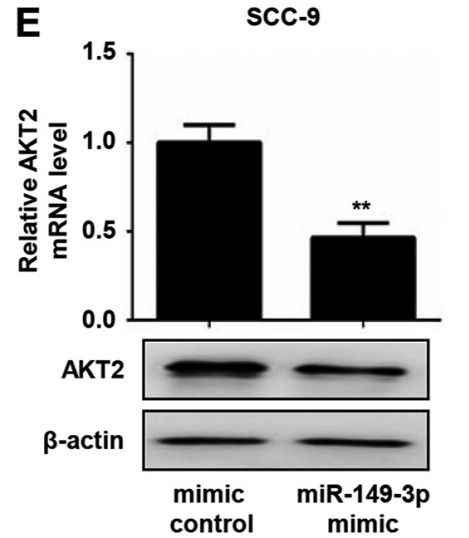

$\mathbf{F}$

Head and neck squamous cell carcinoma

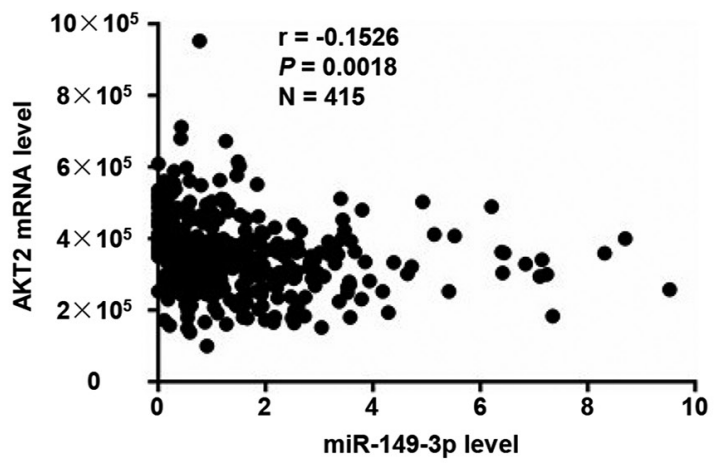

Figure 4. miR-149-3p directly targets AKT2 3'-UTR. (A) Putative binding sites of miR-149-3p in the 3'-UTR of AKT2. (B and C) Relative luciferase activity of Cal27 and SCC-9 cells co-transfected with WT or MT AKT2 3'-UTR and miR-149-3p mimic or mimic control. (D and E) Reverse transcriptionquantitative PCR and western blot analysis of AKT2 mRNA and protein expression levels in Cal27 and SCC-9 cells transfected with miR-149-3p mimic or mimic control. (F) miR-149-3p expression was correlated associated with AKT2 mRNA level in TCGA head and neck squamous cell carcinoma dataset. Data are presented as the mean $\pm \mathrm{SD} .{ }^{*} \mathrm{P}<0.05,{ }^{* *} \mathrm{P}<0.01$ and ${ }^{* * *} \mathrm{P}<0.001$ vs. mimic control. miR-149-3p, microRNA-149-3p; WT, wild-type; MT, mutated; 3'-UTR, 3'-untranslated region.

overexpression of miR-149-3p resulted in a significant decrease in the mRNA and protein expression levels of AKT2 in OSCC cells (Fig. 4D and E). In addition, a weak negative correlation between AKT2 and miR-149-3p expression was observed in a TCGA head and neck squamous cell carcinoma dataset (Fig. 4F). These results suggested that miR-149-3p could regulate AKT2 expression by directly binding to the AKT2 3'-UTR.

AKT2 restores the inhibitory effect of miR-149-3p on the proliferation of OSCC cells. To further examine the involvement of AKT2 in miR-149-3p-mediated cell proliferation, OSCC cells were transfected with AKT2 plasmid or empty pcDNA3 plasmid, and the expression levels of AKT2 were validated by RT-qPCR and western blot analysis. The results revealed that ectopic introduction of AKT2 significantly increased the expression levels of AKT2 in Cal27 and SCC-9 cells (Fig. 5A and B). Enforced AKT2 expression did not alter miR-149-3p expression levels, whereas it rescued the decreased mRNA and protein expression levels of AKT2 induced by miR-149-3p (Fig. 5C-F). In addition, miR-149-3p-induced reduced cell viability was significantly attenuated by AKT2 overexpression in OSCC cells (Fig. 5G and $\mathrm{H}$ ). A similar phenomenon was revealed by the colony formation assay (Fig. 5I). These data indicated that AKT2 was able to reverse the inhibitory effect of miR-149-3p on the proliferation of OSCC cells.

miR-149-3p improves the sensitivity of OSCC cells to 5-Fu by targeting AKT2. To evaluate whether miR-149-3p contributes to the anti-tumor effect of chemotherapeutic agents, Cal27 and SCC-9 cells transfected with miR-149-3p mimic or mimic control were treated with $5-\mathrm{Fu}$ for $24 \mathrm{~h}$. A significant decrease in cell viability of 5-Fu-treated OSCC cells was noted compared with in the non-treated group (Fig. 6A and B). Notably, miR-149-3p mimics enhanced the cytotoxic effects of 5-Fu on OSCC cells (Fig. 6A and B). Moreover, the miR-149-3p mimic synergistically increased 5-Fu-induced elevated expression of cleaved caspase-3 and cleaved PARP (Fig. 6C and D). Flow cytometric analysis indicated that the number of Annexin V-positive OSCC cells was markedly increased following 5-Fu treatment in a dose- and time-dependent manner (Fig. 6E-H). Notably, the miR-149-3p mimic combined with $5-\mathrm{Fu}$ exhibited an additive effect on the apoptosis of OSCC cells (Fig. 6E-H). Subsequently, the effects of AKT2 were evaluated on miR-149-3p-modulated cell death following 5-Fu treatment. AKT2 overexpression effectively rescued the reduced survival of OSCC cells caused by miR-149-3p in the presence of 5-Fu (Fig. 7A and B). In addition, the exogenous introduction of AKT2 significantly reversed the activated caspase- 3 and PARP proteins in miR-149-3p-expressing Cal27 and SCC-9 cells following 5-Fu administration (Fig. 7C and D). These data revealed that miR-149-3p sensitized OSCC cells to 5-Fu by targeting AKT2.

\section{Discussion}

miRNA biogenesis refers to the process of producing a mature and functional miRNA and includes primary miRNA 
A

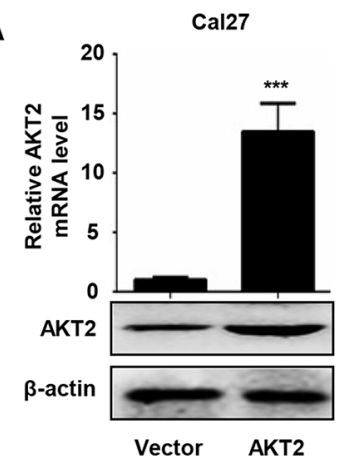

E
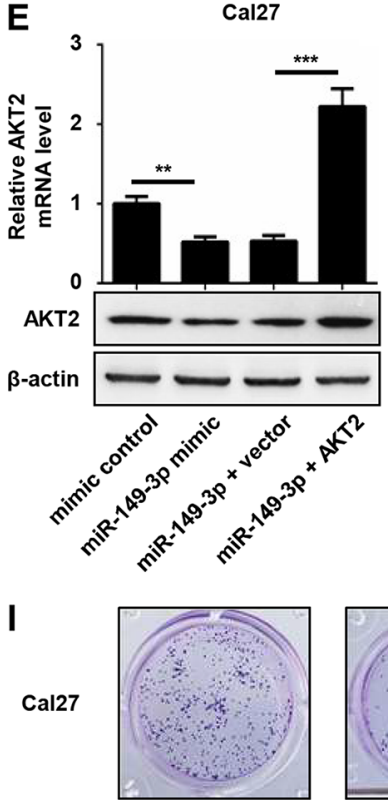

$\operatorname{scc}-9$

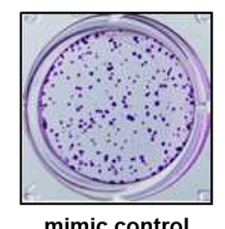

B

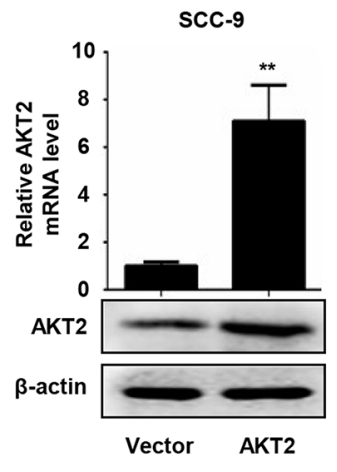

F

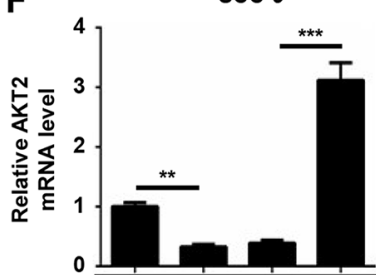

AKT2

$\beta$-actin

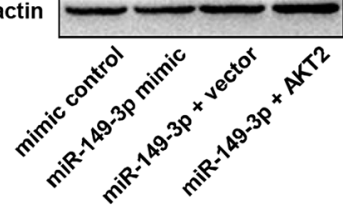

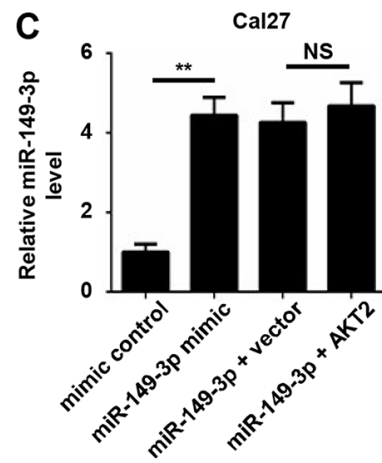

G

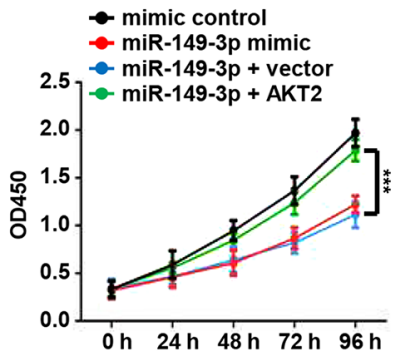

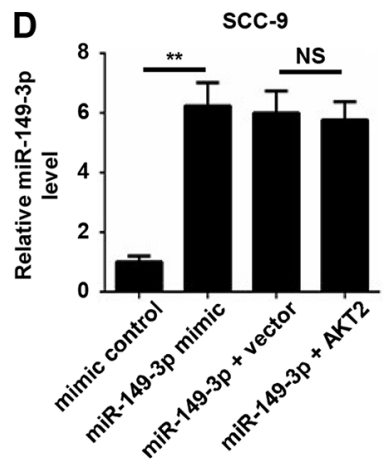

H

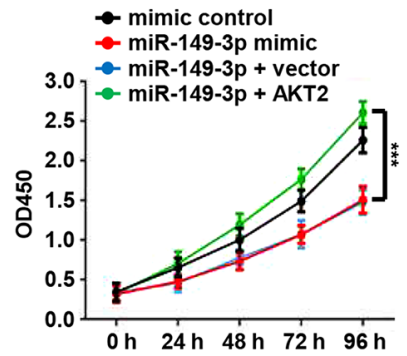

mimic control
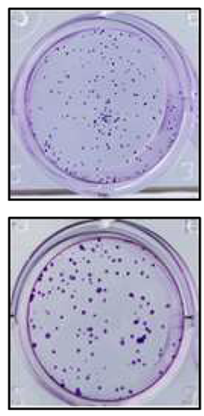

miR-149-3p mimic
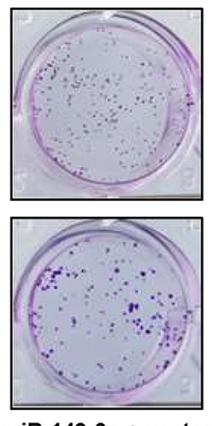
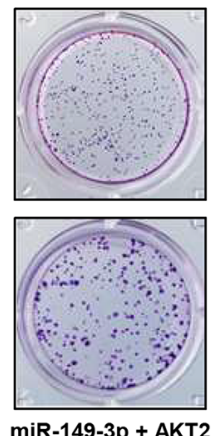

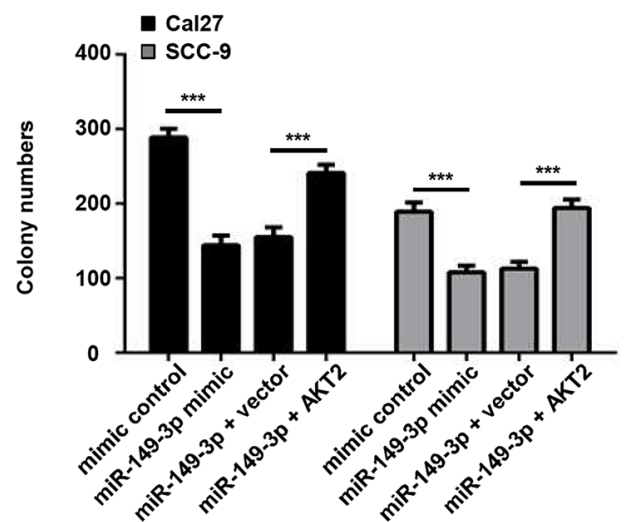

Figure 5. AKT2 restores the decreased proliferation induced by miR-149-3p mimic in oral squamous cell carcinoma cells. (A and B) Reverse transcription-quantitative PCR and western blot analyses of AKT2 expression levels in Cal27 and SCC-9 cells transfected with AKT2 plasmid or empty pcDNA3 plasmid. (C and D) Reverse transcription-quantitative PCR analysis of miR-149-3p expression levels in Cal27 and SCC-9 cells co-transfected with miR-149-3p mimic and AKT2 plasmid or empty pcDNA3 plasmid. (E and F) Reverse transcription-quantitative PCR and western blot analyses of AKT2 expression levels in Cal27 and SCC-9 cells co-transfected with miR-149-3p mimic and AKT2 plasmid or empty pcDNA3 plasmid. (G and H) Viability of Cal27 and SCC-9 cells co-transfected with miR-149-3p mimic and AKT2 plasmid or empty pcDNA3 plasmid, as determined using a Cell Counting Kit-8 assay. (I) Proliferation of Ca127 and SCC-9 cells co-transfected with miR-149-3p mimic and AKT2 plasmid or empty pcDNA3 plasmid was examined using a colony formation assay. Data are presented as the mean $\pm \mathrm{SD} .{ }^{* * *} \mathrm{P}<0.01$ and ${ }^{* * *} \mathrm{P}<0.001$ vs. vector or as indicated. miR-149-3p, microRNA-149-3p; NS, non-significant.

transcription and cleavage, and precursor miRNA export and processing. It has been proposed that miRNA biogenesis is caused when the guide strand derived from duplex miRNA directly binds and represses the target mRNA at the translational level, whereas the passenger strand of miRNA is degraded and displays no function $(18,19)$. In contrast to this theory, accumulating evidence has revealed that the passenger strand of certain precursor miRNAs contributes to the development of several types of cancer $(20,21)$. A previous study demonstrated that both miR-149-5p (the guide strand) and miR-149-3p (the passenger strand) resulted in decreased migratory and invasive capacities by degrading the mRNA expression of FoxM1 in clear cell renal cell carcinoma (22).
Moreover, miR-149-5p enhanced chemotherapeutic resistance through inactivation of the Hippo signaling pathway in ovarian cancer (23), whereas high levels of miR-149-3p were associated with the aggressive progression and poor prognosis of ovarian cancer (24). These results indicated a similar function between miR-149-3p and miR-149-5p. However, miR-149-5p and miR-149-3p exhibit diverse roles in cancer progression. For example, long intergenic non-protein-coding RNA 472 inhibited tumor growth and metastasis by sponging and decreasing miR-149-3p expression, leading to the upregulation of KLLN and activation of p53 signaling in non-small cell lung cancer (NSCLC) cells, which suggested an oncogenic function of miR-149-3p (25). Conversely, 
A

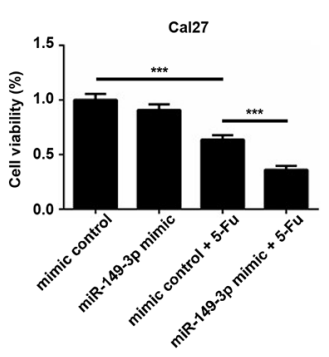

B

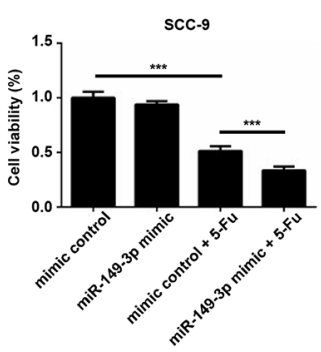

C

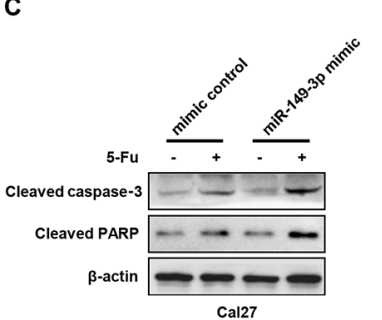

cal27
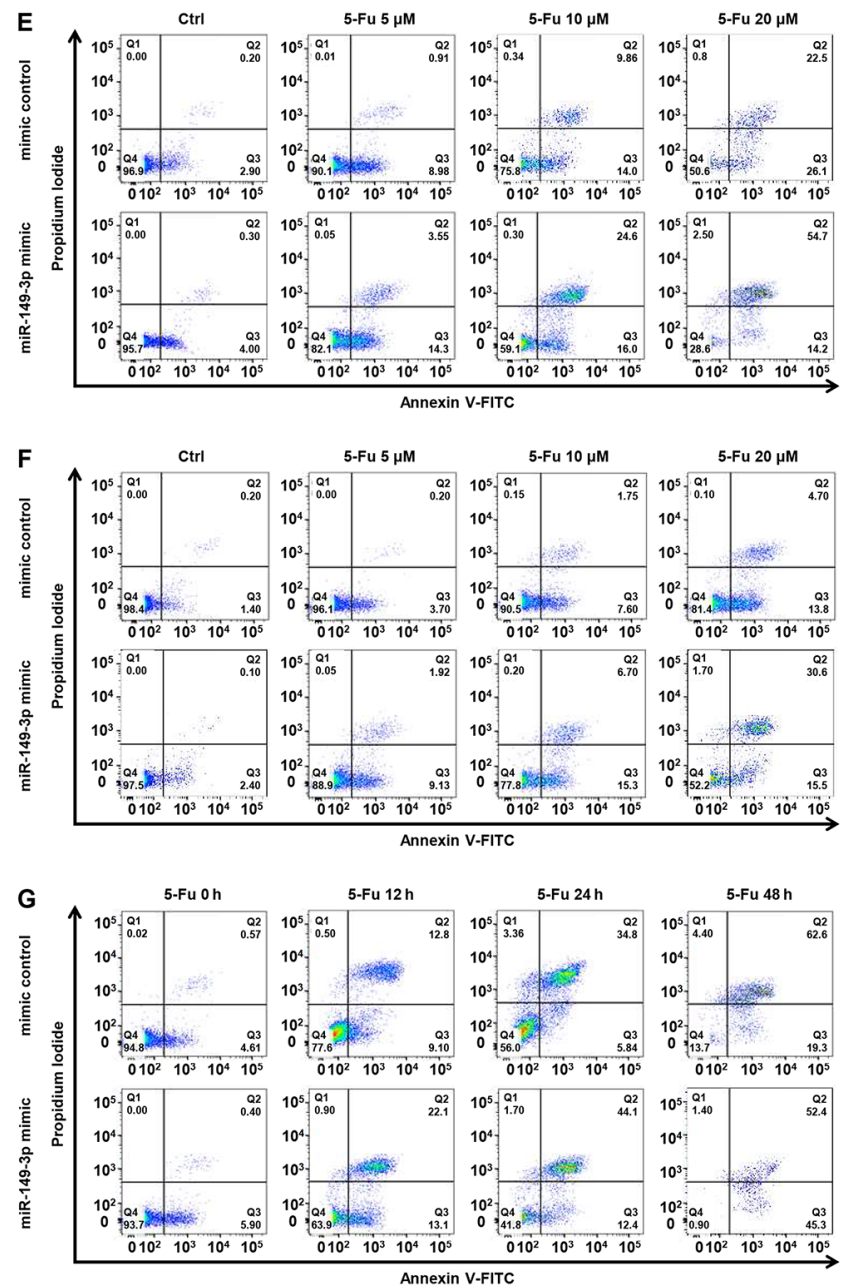

Annexin V-FITC
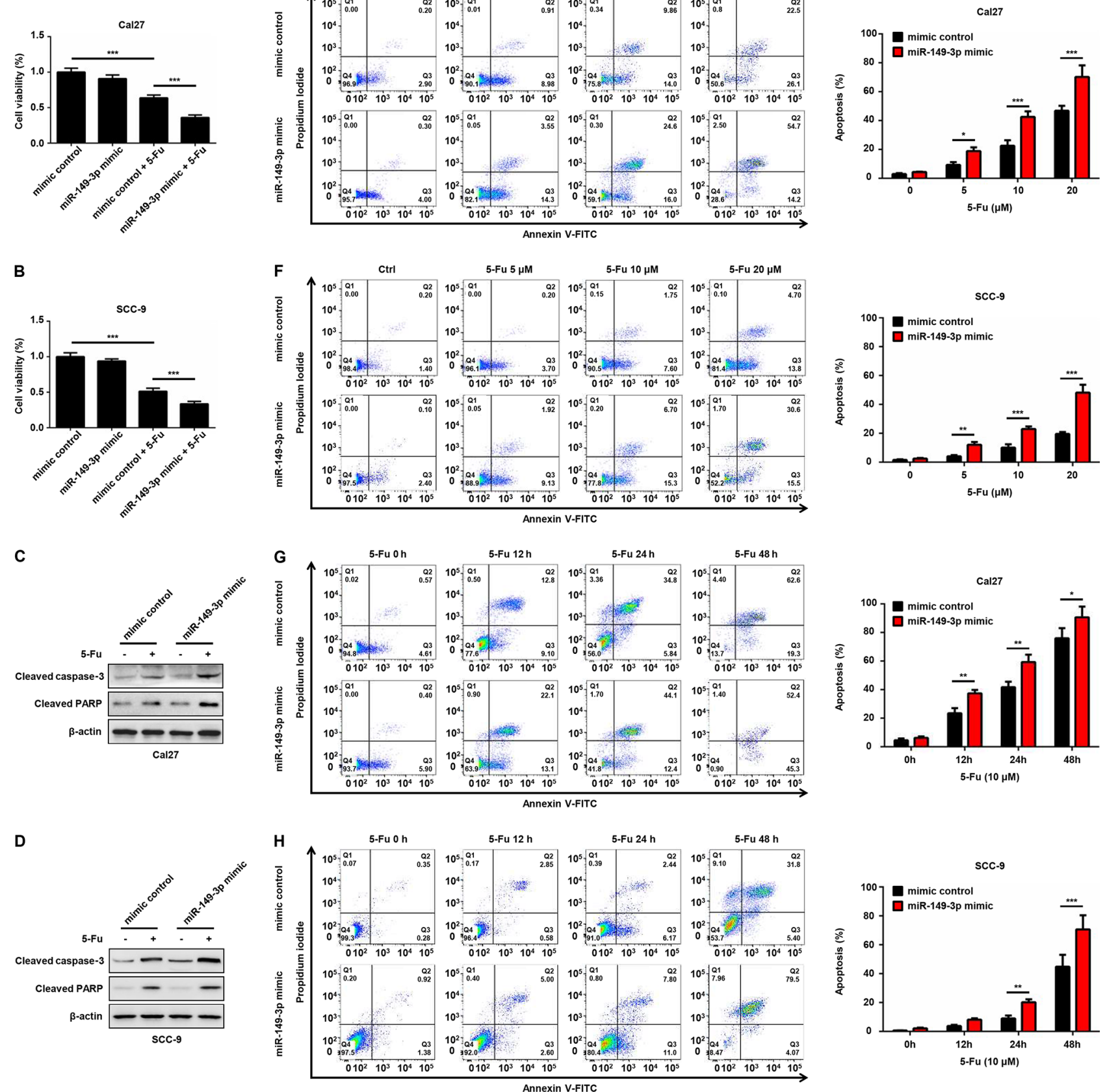

Figure 6. miR-149-3p improves the sensitivity of oral squamous cell carcinoma cells to 5-Fu. (A and B) Cal27 and SCC-9 cells were transfected with miR-149-3p mimic or mimic control and were then treated with 5-Fu for $24 \mathrm{~h}$. Cell viability was determined using a Cell Counting Kit-8 assay. (C and D) Cal27 and SCC-9 cells were transfected with miR-149-3p mimic or mimic control and were treated with 5-Fu for $24 \mathrm{~h}$. The protein expression levels of cleaved caspase-3 and cleaved PARP were detected by western blot analysis. (E and F) Cal27 and SCC-9 cells were transfected with miR-149-3p mimic or mimic control and were treated with increasing concentrations of 5-Fu for $24 \mathrm{~h}$. The number of apoptotic cells was determined using an Annexin V assay. (G and $\mathrm{H}$ ) Cal27 and SCC-9 cells were transfected with miR-149-3p mimic or mimic control and were treated with $10 \mu \mathrm{M}$ 5-Fu for the indicated time. The number of apoptotic cells $(\mathrm{Q} 2+\mathrm{Q} 3)$ was determined using an Annexin V assay. Data are presented as the mean $\pm \mathrm{SD} .{ }^{*} \mathrm{P}<0.05,{ }^{* *} \mathrm{P}<0.01$ and ${ }^{* * *} \mathrm{P}<0.001$. miR-149-3p, microRNA-149-3p; 5-Fu, 5-fluorouracil.

miR-149-5p acted as a tumor suppressor in $\operatorname{NSCLC~}(26,27)$. In the present study, the data demonstrated that miR-149-3p overexpression reduced the viability and colony formation of OSCC cells, whereas knockdown of miR-149-3p induced the proliferation of OSCC cells. Recent studies have revealed that lower levels of miR-149-5p were observed in OSCC tumor tissues compared with in adjacent normal tissues (28), whereas miR-149-5p overexpression resulted in attenuated proliferation and motility, as well as increased drug sensitivity, in OSCC cells (29). These data, together with the present findings, indicated the tumor-suppressive functions of miR-149-5p and miR-149-3p in OSCC, and suggested that the dual strand of miR-149 may be a potential biomarker for the generation and development of OSCC.

The AKT family is an evolutionarily conserved serine/threonine kinase family that contains three isoforms (AKT1, AKT2 and AKT3). Emerging evidence has revealed that the upregulation of AKT2 is essential for tumorigenesis, 
A
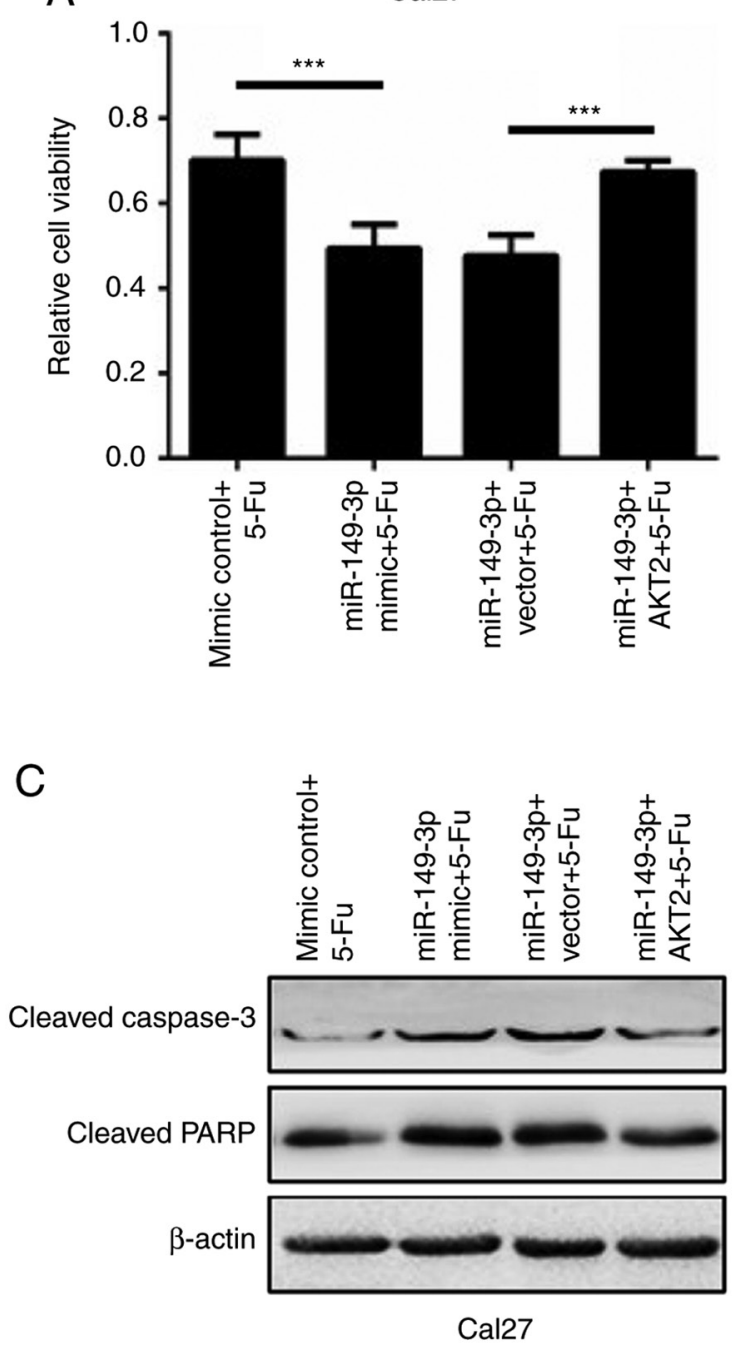

B

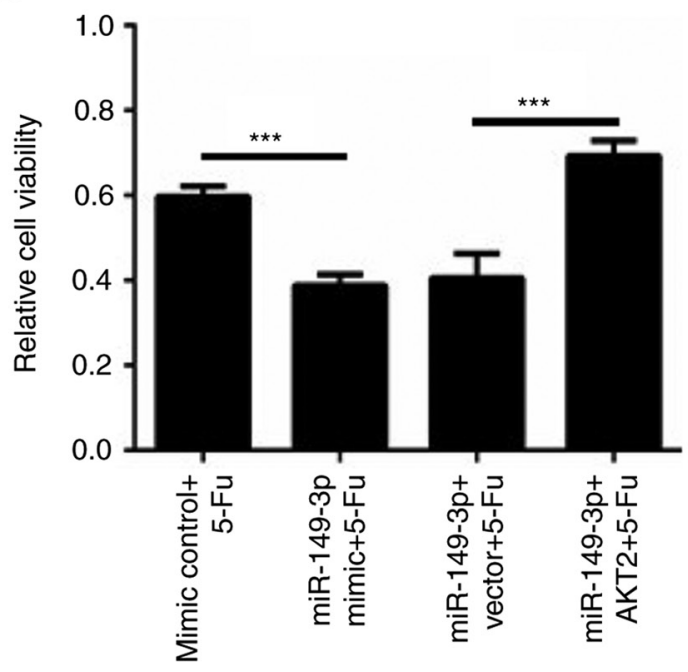

D
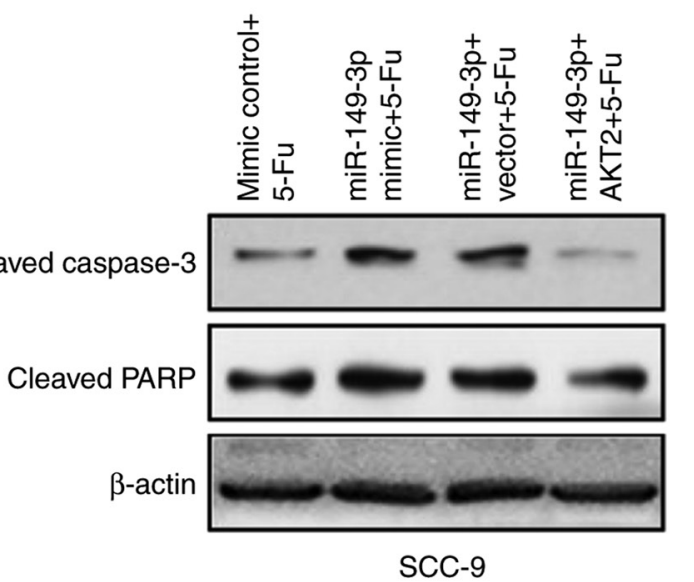

Figure 7. AKT2 attenuates miR-149-3p-mediated sensitivity of oral squamous cell carcinoma cells to 5-Fu. (A and B) Cal27 and SCC-9 cells were co-transfected with miR-149-3p mimic and AKT2 plasmid or empty pcDNA3 plasmid, and were subsequently treated with 5-Fu for 24 h. Cell viability was determined using a Cell Counting Kit-8 assay and normalized to non-5-Fu treatment group. (C and D) Cal27 and SCC-9 cells were co-transfected with miR-149-3p mimic and AKT2 plasmid or empty pcDNA3 plasmid, and were treated with 5-Fu for $24 \mathrm{~h}$. The protein expression levels of cleaved caspase-3 and cleaved PARP were detected by western blot analysis. Data are presented as the mean $\pm \mathrm{SD}$. ${ }^{* * *} \mathrm{P}<0.001$. miR-149-3p, microRNA-149-3p; 5-Fu, 5-fluorouracil.

angiogenesis and metastasis, and it has been reported to act as an oncogene in several types of cancer, including hepatocellular carcinoma (30), ovarian cancer (31) and breast cancer (32). In the present study, the results demonstrated that the miR-149-3p mimic significantly suppressed the mRNA and protein expression levels of AKT2. In addition, miR-149-3p decreased the luciferase activity of WT AKT2 3'-UTR, whereas this effect was not noted in the MT AKT2 3'-UTR, suggesting that AKT2 was a direct target of miR-149-3p. AKT2 overexpression reversed the miR-149-3p-mediated inhibitory effect on the proliferation of OSCC cells. These findings further supported the hypothesis that AKT2 contributes to OSCC progression. In line with the present observations, AKT2 was previously shown to be upregulated and activated in OSCC tissues (33), whereas the reduced expression of AKT2 induced by caffeic acid phenethyl ester suppressed proliferation and the survival of OSCC cells (34). Moreover, the CXCL9/CXCR3 axis promoted invasion and metastasis through AKT2-mediated epithelial-mesenchymal transition in tongue squamous cell carcinoma (35). Since AKT2 mRNA has been demonstrated to be regulated by diverse miRNAs, such as miR-194 (36), miR-625-5p (37) and miR-92a (38), the crosstalk of these miRNAs that controls the translational repression of AKT2 requires further exploration.

5-Fu is one of the first-line chemotherapeutic drugs used for the treatment of OSCC. Although this drug significantly improves the survival of patients with OSCC, resistance to 5-Fu inevitably occurs following the treatment of patients over a long period of time $(39,40)$. Moreover, the undesired side effects, including mouth sores, vomiting, nausea and diarrhea, limit the clinical application of 5-Fu. Increased sensitivity of OSCC cells to chemotherapeutic drugs is a potential strategy to improve chemoresistance. In the present study, the results demonstrated that the miR-149-3p mimic strengthened 5-Fu-induced decreased cell viability, and increased protein expression levels of cleaved caspase- 3 and cleaved PARP. Caspase- 3 is a critical executioner of apoptosis, and activation of caspase 3 requires proteolytic processing of its inactive zymogen (total caspase-3) into activated fragments (cleaved caspase-3). PARP 
is one of the main cleavage targets of activated caspase-3, and cleavage of PARP facilitates cellular disassembly and promotes cell apoptosis $(41,42)$. As cleaved caspase-3 and cleaved PARP are two representative markers of apoptosis, the present data further supported that miR-149-3p contributed to 5-Fu-mediated cell apoptosis. However, this effect was reversed by AKT2 overexpression, suggesting that miR-149-3 improved the cytotoxic effects of 5-Fu on OSCC cells by targeting AKT2. In agreement with these findings, the methylation-mediated epigenetic silencing of miR-149-3p was previously discovered to be involved in chemoresistance in breast cancer cells (43). In addition, the decreased expression of miR-149-3p was noted in cisplatin-resistant colon cancer cells (44). Therefore, these observations indicated that miR-149-3p may be a promising target for overcoming chemotherapy resistance.

In conclusion, the present study revealed a novel molecular pathway by which miR-149-3p suppressed the proliferation of OSCC cells. The mechanism of action involved the negative regulation of AKT2 mRNA expression. Furthermore, miR-149-3p enhanced the sensitivity of OSCC cells to 5-Fu. Therefore, these findings demonstrated an important role of miR-149-3p during OSCC progression and suggested that the restoration of miR-149-3p expression may be an effective therapeutic strategy for the treatment of OSCC.

\section{Acknowledgements}

Not applicable.

\section{Funding}

This study was supported by the Basic Research Project of Science and Technology Plan of Shenzhen Bao'an District (grant nos. 2019JD430 and 2019JD440) and the Medical Scientific Research Foundation of Guangdong Province (grant no. A2020290).

\section{Availability of data and materials}

The datasets used and/or analyzed during the present study are available from the corresponding author on reasonable request.

\section{Authors' contributions}

QS and WS conceived and designed the study. QS and HZ performed the experiments and analyzed the data. QS, QL, LC and DY interpreted the data. QS wrote the manuscript. All authors read and approved the final manuscript.

\section{Ethics approval and consent to participate}

Not applicable.

\section{Patient consent for publication}

Not applicable.

\section{Competing interests}

The authors declare that they have no competing interests.

\section{References}

1. Siegel RL, Miller KD and Jemal A: Cancer statistics, 2018. CA Cancer J Clin 68: 7-30, 2018.

2. Iamaroon A and Krisanaprakornkit S: Overexpression and activation of Akt2 protein in oral squamous cell carcinoma. Oral Oncol 45: e175-e179, 2009.

3. Leemans CR, Braakhuis BJ and Brakenhoff RH: The molecular biology of head and neck cancer. Nat Rev Cancer 11: 9-22, 2011.

4. Carvalho AL, Nishimoto IN, Califano JA and Kowalski LP: Trends in incidence and prognosis for head and neck cancer in the United States: A site-specific analysis of the SEER database. Int J Cancer 114: 806-816, 2005.

5. Rupaimoole R and Slack FJ: MicroRNA therapeutics: Towards a new era for the management of cancer and other diseases. Nat Rev Drug Discov 16: 203-222, 2017.

6. Gebert LFR and MacRae IJ: Regulation of microRNA function in animals. Nat Rev Mol Cell Biol 20: 21-37, 2019.

7. Nishiwada S, Sho M, Banwait JK, Yamamura K, Akahori T, Nakamura K, Baba H and Goel A: A microRNA signature identifies pancreatic ductal adenocarcinoma patients at risk for lymph node metastases. Gastroenterology 159: 562-574, 2020.

8. Zhao M, Hou Y, Du YE, Yang L, Qin Y, Peng M, Liu S, Wan X, Qiao Y, Zeng H, et al: Drosha-independent miR-6778-5p strengthens gastric cancer stem cell stemness via regulation of cytosolic one-carbon folate metabolism. Cancer Lett 478: 8-21, 2020.

9. Xu Y, Ji K, Wu M, Hao B, Yao KT and Xu Y: A miRNA-HERC4 pathway promotes breast tumorigenesis by inactivating tumor suppressor LATS1. Protein Cell 10: 595-605, 2019.

10. Shin CH, Lee H, Kim HR, Choi KH, Joung JG and Kim HH: Regulation of PLK1 through competition between hnRNPK, miR-149-3p and miR-193b-5p. Cell Death Differ 24: 1861-1871, 2017.

11. Yang D, Du G, Xu A, Xi X and Li D: Expression of miR-149-3p inhibits proliferation, migration, and invasion of bladder cancer by targeting S100A4. Am J Cancer Res 7: 2209-2219, 2017.

12. Zhang M, Gao D, Shi Y, Wang Y, Joshi R, Yu Q, Liu D, Alotaibi F, Zhang Y, Wang H, et al: miR-149-3p reverses CD8+ T-cell exhaustion by reducing inhibitory receptors and promoting cytokine secretion in breast cancer cells. Open Biol 9: 190061, 2019.

13. Bellazzo A, Di Minin G, Valentino E, Sicari D, Torre D, Marchionni L, Serpi F, Stadler MB, Taverna D, Zuccolotto G, et al: Cell-autonomous and cell non-autonomous downregulation of tumor suppressor DAB2IP by microRNA-149-3p promotes aggressiveness of cancer cells. Cell Death Differ 25: 1224-1238, 2018.

14. Livak KJ and Schmittgen TD: Analysis of relative gene expression data using real-time quantitative PCR and the 2(-Delta Delta C(T)) Method. Methods 25: 402-408, 2001.

15. Cancer Genome Atlas Network: Comprehensive genomic characterization of head and neck squamous cell carcinomas. Nature 517: 576-582, 2015.

16. Gonzalez E and McGraw TE: The Akt kinases: Isoform specificity in metabolism and cancer. Cell Cycle 8: 2502-2508, 2009.

17. Hers I, Vincent EE and Tavaré JM: Akt signalling in health and disease. Cell Signal 23: 1515-1527, 2011.

18. Lin S and Gregory RI: MicroRNA biogenesis pathways in cancer. Nat Rev Cancer 15: 321-333, 2015.

19. Bartel DP: MicroRNAs: Target recognition and regulatory functions. Cell 136: 215-233, 2009.

20. Sugawara S, Yamada Y, Arai T, Okato A, Idichi T, Kato M, Koshizuka K, Ichikawa T and Seki N: Dual strands of the miR-223 duplex (miR-223-5p and miR-223-3p) inhibit cancer cell aggressiveness: Targeted genes are involved in bladder cancer pathogenesis. J Hum Genet 63: 657-668, 2018.

21. Okato A, Arai T, Kojima S, Koshizuka K, Osako Y, Idichi T, Kurozumi A, Goto Y, Kato M, Naya Y, et al: Dual strands of pre-miR150 (miR1505p and miR1503p) act as antitumor miRNAs targeting SPOCK1 in naive and castration-resistant prostate cancer. Int J Oncol 51: 245-256, 2017.

22. Okato A, Arai T, Yamada Y, Sugawara S, Koshizuka K, Fujimura L, Kurozumi A, Kato M, Kojima S, Naya Y, et al: Dual Strands of Pre-miR-149 inhibit cancer cell migration and invasion through targeting FOXM1 in renal cell carcinoma. Int J Mol Sci 18: 1969, 2017.

23. Xu M, Xiao J, Chen M, Yuan L, Li J, Shen H and Yao S: miR1495p promotes chemotherapeutic resistance in ovarian cancer via the inactivation of the Hippo signaling pathway. Int J Oncol 52: 815-827, 2018. 
24. Li Y, Liu C, Liao Y, Wang W, Hu B, Lu X and Cui J: Characterizing the landscape of peritoneal exosomal microRNAs in patients with ovarian cancer by high-throughput sequencing. Oncol Lett 17: 539-547, 2019.

25. Zou A, Liu X, Mai Z, Zhang J, Liu Z, Huang Q, Wu A and Zhou C: LINC00472 Acts as a Tumor Suppressor in NSCLC through KLLN-Mediated p53-Signaling Pathway via MicroRNA-149-3p and MicroRNA-4270. Mol Ther Nucleic Acids 17: 563-577, 2019.

26. Liu L, Chen Y, Li Q and Duan P: IncRNA HNF1A-AS1 modulates non-small cell lung cancer progression by targeting miR-149-5p/Cdk6. J Cell Biochem 120: 18736-18750, 2019.

27. Li J, Li Y, Wang B, Ma Y and Chen P: lncRNA-PCAT-1 promotes non-small cell lung cancer progression by regulating miR-149-5p/LRIG2 axis. J Cell Biochem: Dec 19, 2018 (Epub ahead of print).

28. Lai H, Xu G, Meng H and Zhu H: Association of SP1 rs1353058818 and STAT3 rs1053004 gene polymorphisms with human tongue squamous cell carcinoma. Biosci Rep 23: 39, 2019.

29. Luo K, He J, Yu D and Acil Y: MiR-149-5p regulates cisplatin chemosensitivity, cell growth, and metastasis of oral squamous cell carcinoma cells by targeting TGF $\beta 2$. Int J Clin Exp Pathol 12: 3728-3739, 2019

30. Wang Q, Yu WN, Chen X, Peng XD, Jeon SM, Birnbaum MJ, Guzman G and Hay N: Spontaneous hepatocellular carcinoma after the combined deletion of Akt isoforms. Cancer Cell 29 $523-535,2016$

31. Lin X, Shen J, Dan Peng, He X, Xu C, Chen X, Tanyi JL, Montone K, Fan Y, Huang Q, Zhang L and Zhong X: RNA-binding protein LIN28B inhibits apoptosis through regulation of the AKT2/FOXO3A/BIM axis in ovarian cancer cells. Signal Transduct Target Ther 3: 23, 2018.

32. Chen X, Ariss MM, Ramakrishnan G, Nogueira V, Blaha C, Putzbach W, Islam ABMMK, Frolov MV and Hay N: Cell-autonomous versus systemic akt isoform deletions uncovered new roles for Akt1 and Akt2 in Breast Cancer. Mol Cell 80 87-101.e5, 2020

33. Roy NK, Monisha J, Padmavathi G, Lalhruaitluanga H, Kumar NS, Singh AK, Bordoloi D, Baruah MN, Ahmed GN, Longkumar I, et al: Isoform-specific role of akt in oral squamous cell carcinoma. Biomolecules 9: 253, 2019.

34. Kuo YY, Lin HP, Huo C, Su LC, Yang J, Hsiao PH, Chiang HC, Chung CJ, Wang HD, Chang JY, et al: Caffeic acid phenethyl ester suppresses proliferation and survival of TW2.6 human oral cancer cells via inhibition of Akt signaling. Int J Mol Sci 14 8801-8817, 2013.

35. Li Z, Liu J, Li L, Shao S, Wu J, Bian L and He Y: Epithelial mesenchymal transition induced by the CXCL9/CXCR3 axis through AKT activation promotes invasion and metastasis in tongue squamous cell carcinoma. Oncol Rep 39: 1356-1368, 2018.
36. Wu JC, Chen R, Luo X, Li ZH, Luo SZ and Xu MY: MicroRNA-194 inactivates hepatic stellate cells and alleviates liver fibrosis by inhibiting AKT2. World J Gastroenterol 25: 4468-4480, 2019.

37. Qian FH, Deng X, Zhuang QX, Wei B and Zheng DD: miR6255p suppresses inflammatory responses by targeting AKT2 in human bronchial epithelial cells. Mol Med Rep 19: 1951-1957, 2019

38. Yu FY, Xie CQ, Jiang CL, Sun JT, Feng HC, Li C and Huang XW: MiR-92a inhibits fibroblast-like synoviocyte proliferation and migration in rheumatoid arthritis by targeting AKT2. J Biosci 43 : 911-919, 2018.

39. Nagata M, Nakayama H, Tanaka T, Yoshida R, Yoshitake $Y$, Fukuma D, Kawahara K, Nakagawa Y, Ota K, Hiraki A and Shinohara M: Overexpression of cIAP2 contributes to 5-FU resistance and a poor prognosis in oral squamous cell carcinoma. Br J Cancer 105: 1322-1330, 2011.

40. Feng X, Luo Q, Zhang H, Wang H, Chen W, Meng G and Chen F: The role of NLRP3 inflammasome in 5-fluorouracil resistance of oral squamous cell carcinoma. J Exp Clin Cancer Res 36: 81, 2017.

41. Fernandes-Alnemri T, Litwack G and Alnemri ES: CPP32, a novel human apoptotic protein with homology to Caenorhabditis elegans cell death protein Ced-3 and mammalian interleukin-1 beta-converting enzyme. J Biol Chem 269: 30761-30764, 1994.

42. Nicholson DW, Ali A, Thornberry NA, Vaillancourt JP, Ding CK, Gallant M, Gareau Y, Griffin PR, Labelle M, Lazebnik YA, et al: Identification and inhibition of the ICE/CED-3 protease necessary for mammalian apoptosis. Nature 376: 37-43, 1995.

43. He DX, Gu XT, Li YR, Jiang L, Jin J and Ma X: Methylation-regulated miR-149 modulates chemoresistance by targeting GlcNAc N-deacetylase/N-sulfotransferase-1 in human breast cancer. FEBS J 281: 4718-4730, 2014.

44. Liu Y, Yang C, Zhao Y, Chi Q, Wang Z and Sun B Overexpressed methyltransferase-like 1 (METTL1) increased chemosensitivity of colon cancer cells to cisplatin by regulating miR-149-3p/S100A4/p53 axis. Aging (Albany NY) 11: 12328-12344, 2019.

This work is licensed under a Creative Commons Attribution-NonCommercial-NoDerivatives 4.0 International (CC BY-NC-ND 4.0) License. 